\title{
Fronto-orbitozygomatic approach: functional and cosmetic outcomes in a series of 169 patients
}

\author{
Nicola Boari, MD, Alfio Spina, MD, Lodoviga Giudice, MD, Francesca Gorgoni, MD, \\ Michele Bailo, MD, and Pietro Mortini, MD \\ Department of Neurosurgery, I.R.C.C.S. San Raffaele University Hospital, Vita-Salute University, Milan, Italy
}

\begin{abstract}
OBJECTIVE Advantages of the fronto-orbitozygomatic (FOZ) approach have been reported extensively in the literature; nevertheless, restoration of normal anatomy and the esthetic impact of surgery are increasingly important issues for patients and neurosurgeons. The aim of this study was to analyze functional and cosmetic outcomes in a series of 169 patients with different pathologies who underwent surgery in which the FOZ approach was used.
\end{abstract}

METHODS Between January 2000 and December 2014, 250 consecutive patients underwent surgery with an FOZ approach as the primary surgical treatment. Follow-up data were available for only 169 patients; 103 (60.9\%) of these patients were female and 66 (39.1\%) were male, and their ages ranged from 6 to 77 years (mean 46.9 years; SD 15.6 years). Mean follow-up time was 66 months (range 6-179 months; SD 49.5 months). Evaluation of clinical outcomes was performed with a focus on 4 main issues: surgical complications, functional outcome, cosmetic outcome, and patient satisfaction. The additional time needed to perform orbitotomy and orbital reconstruction was also evaluated.

RESULTS The permanent postoperative complications included forehead hypesthesia (41.4\%) and dysesthesia (15.3\%), frontal muscle weakness (10.3\%), exophthalmos (1.4\%), enophthalmos $(4.1 \%)$, diplopia $(6.6 \% ; 2 \%$ were related to surgical approach), and persistent periorbital and eyelid swelling (3\%). Approximately $90 \%$ of the patients reported subjectively that surgery did not affect their quality of life or complained of only minor problems that did not influence their quality of life significantly. The mean time needed for orbitotomy and orbital reconstruction was approximately half an hour.

CONCLUSIONS Comprehensive knowledge of the potential complications and overall clinical outcomes of the FOZ approach can be of great utility to neurosurgeons in balancing the well-known benefits of the approach with potential additional morbidities.

https://thejns.org/doi/abs/10.3171/2016.9.JNS16622

KEY WORDS fronto-orbitozygomatic approach; skull base surgery; functional outcome; cosmetic outcome; surgical technique

$I^{\prime}$ N 1912, McArthur ${ }^{32}$ reported performing a right frontal osteoplastic flap by resecting the supraorbital rim and part of the orbital roof to access the pituitary gland from an extradural approach ${ }^{6}$ (probably the first cranioorbital approach). In 1969, Yaşargil ${ }^{54}$ described the frontolateral sphenoorbital approach, known worldwide as the pterional approach. ${ }^{6}$ Over the past 4 decades, several authors have reviewed the pterional approach and offered slight modifications in the flap procedure. ${ }^{5,6,38,41}$ Pellerin et al. ${ }^{39}$ used an orbitofrontomalar approach with a bitemporal scalp incision, which was basically a fronto-orbitozygomatic (FOZ) flap with the superior orbital ridge included. Hakuba et al. ${ }^{26}$ described the orbitozygomatic infratempo- ral approach. Al-Mefty ${ }^{2}$ described the cranio-orbitozygomatic approach including the superior and lateral orbital rims, the anterior portion of the orbital roof, and the adjacent frontal and temporal bones in the flap.

The 1990s were the "golden era" of skull base surgery, characterized by the development of many complex skull base approaches aimed to enhance the exposure of central and deep structures to minimize brain retraction. ${ }^{12,15,18,43}$

Enthusiasm related to the application of these approaches led to their increasing and not infrequently uncritical use and an increase of approach-related complications. ${ }^{43}$ The following period was characterized by a routine but critical use of complex skull base approaches and an in- 
creasing reuse of standard approaches. ${ }^{43,56}$ Nowadays, complex skull base approaches are used in very select cases in which the invasiveness and risks of extensive cranial disassembly are counterbalanced by significant advantages in the treatment of the pathology. ${ }^{36}$ Over time, the FOZ approach has been considered the true workhorse of skull base surgery because of its simple execution, great versatility, and low rate of associated morbidity. ${ }^{1-5,9,14,19,21-24,26,28 \text {, }}$ 31,38,40,42,43,45-48,50-52,56,57 Most published studies have focused on the surgical technique and the gained exposure., ${ }^{1,4,5,-9,11-}$ 14,17,19,21-28,30,31,34-37,40-43,45,48,50,51,56,57 Many technical variants of the FOZ approach have been described in the literature, and its advantages have been extensively reported; nevertheless, few studies have focused on functional and cosmetic outcomes. ${ }^{56}$ Preservation of neurological functions, restoration of normal anatomy, and the esthetic impact of surgery are all increasingly important issues for the patient and the neurosurgeon. ${ }^{10,11,36,56}$ The aim of this study was to analyze the clinical outcome of the FOZ approach in a large series of 169 patients who underwent surgery at the same center within a 14-year period; the study focused on approach-related complications as determinants of functional and cosmetic outcomes and on patient satisfaction.

\section{Methods}

We retrospectively reviewed hospital records of 250 consecutive patients who underwent surgery in which an FOZ approach was used as the primary surgical treatment for different pathologies between January 2000 and December 2014 at I.R.C.C.S. San Raffaele University Hospital. Patients who had undergone previous transcranial surgery were excluded from the study to avoid bias in the evaluation of approach-related morbidity. In 79 (46.7\%) patients, the FOZ approach was followed by extradural optic nerve decompression in which the optic canal was unroofed. Data on clinical history, symptoms, signs, and early postoperative outcome were obtained retrospectively by review of clinical records and radiological images. Follow-up data were available for only 169 patients and were obtained by clinical examinations, review of postoperative radiological study results, and telephone interviews. Physicians indirectly involved in the surgical procedures assessed the clinical and functional outcomes of patients treated through the FOZ approach. In patients with a pathology that caused visual impairment, independent ophthalmological evaluation was performed by neuroophthalmologists. Postoperative follow-up was at least 6 months, after which we considered approach-related complications and functional and cosmetic results to have been stabilized. One hundred three $(60.9 \%)$ patients were female, and 66 (39.1\%) were male; their ages ranged from 6 to 77 years (mean 46.9 years; SD 15.6 years). Table 1 summarizes the pathologies treated through the FOZ approach; $50 \%$ of the patients had skull base meningioma. In $112(66.3 \%)$ patients, the FOZ approach was performed on the right side, and in 57 (33.7\%) patients, the approach was on the left side. Preoperative neurological signs in all patients were recorded to exclude them when we evaluated approach-related morbidities at follow-up. The mean follow-up duration was 66 months (range 6-179 months;
TABLE 1. Patient characteristics

\begin{tabular}{|c|c|c|}
\hline Characteristic & No. & $\%$ \\
\hline \multicolumn{3}{|l|}{ Population data } \\
\hline No. of patients & 169 & - \\
\hline \multicolumn{3}{|l|}{ Sex } \\
\hline Female & 103 & 60.9 \\
\hline Male & 66 & 39.1 \\
\hline Mean age (yrs) & 46.9 & - \\
\hline Mean follow-up (mos) & 66 & - \\
\hline \multicolumn{3}{|l|}{ Side of approach } \\
\hline Right & 112 & 66.3 \\
\hline Left & 57 & 33.7 \\
\hline Optic nerve decompression & 79 & 46.7 \\
\hline \multicolumn{3}{|l|}{ Pathology } \\
\hline Meningioma & 85 & 50.3 \\
\hline Craniopharyngioma & 29 & 17.1 \\
\hline Pituitary adenoma & 23 & 13.6 \\
\hline Orbital cavernoma & 9 & 5.3 \\
\hline Aneurysm & 8 & 4.7 \\
\hline Hypothalamic pilocytic astrocytoma & 4 & 2.4 \\
\hline Fibrous dysplasia & 3 & 1.8 \\
\hline Chordoma & 3 & 1.8 \\
\hline Third ventricle lesions & 3 & 1.8 \\
\hline Intraorbital neurinoma & 2 & 1.2 \\
\hline
\end{tabular}

SD 49.5 months). We also recorded if each postoperative deficit was permanent or transient and, when transient, the time to resolution.

Clinical outcome was assessed with a focus on 4 main issues: surgical complications, functional outcome, cosmetic outcome, and patient satisfaction.

\section{Surgical Complications}

The approach-related complications were ocular movement impairment, frontal muscle weakness, eyebrow motility impairment, forehead skin dysesthesia, visual worsening, and CSF rhinorrhea.

Except for CSF leak, the surgical complications were classified into 1 of 2 groups to indicate that they were a main determinant of functional or cosmetic outcome.

\section{Functional Outcome}

Functional outcome was assessed with a focus on visual worsening, diplopia, postoperative approach-related exophthalmos or enophthalmos, frontal muscle weakness, eyebrow motility impairment, and forehead skin sensitivity impairment.

Exophthalmos and enophthalmos were determined by measuring on an axial MR image, on a section including the lens, the distance between the interzygomatic line and the anterior edge of the eyeball and comparing preoperative and postoperative measurements. ${ }^{10}$ Anterior or posterior dystopia of the eyeball was defined as mild if it was $<2 \mathrm{~mm}$, moderate if it was $\geq 2 \mathrm{~mm}$ but $<4 \mathrm{~mm}$, 
TABLE 2. Assessment criteria for functional outcome

\begin{tabular}{llll} 
& \multicolumn{3}{c}{ Grade } \\
\cline { 2 - 4 } Variable & \multicolumn{1}{c}{ Mild } & Moderate & Severe \\
\hline Eyeball dystopia $(\mathrm{mm})$ & $<2$ & $\geq 2$ but $<4$ & $\geq 4$ \\
\hline Eyebrow motility & $\begin{array}{c}\text { Detectable only through care- } \\
\text { ful neurological exam }\end{array}$ & $\begin{array}{c}\text { Noticeable only in dynamic } \\
\text { situations }\end{array}$ & $\begin{array}{c}\text { Static, evident w/ eyebrow droop; } \\
\text { dynamic, complete frontal paresis }\end{array}$ \\
\hline $\begin{array}{l}\text { Forehead skin dyses- } \\
\text { thesia }\end{array}$ & $\begin{array}{c}\text { Atypical bothersome tactile } \\
\text { feeling }\end{array}$ & $\begin{array}{c}\text { Disturbing sensation even } \\
\text { w/o any tactile stimulus }\end{array}$ & Painful sensation \\
\hline
\end{tabular}

and severe if it was $\geq 4 \mathrm{~mm}$. Eyebrow motility impairment was classified as mild when the frontal muscle weakness was detectable only through careful neurological examination, moderate when it was noticeable only in dynamic situations, and severe when it was evident even when static with eyebrow droop and complete frontal paresis in dynamic situations. Forehead skin dysesthesia was classified as mild when the patient complained of an atypical, bothersome tactile feeling, moderate when it was felt as a disturbing sensation even without any tactile stimulus, and severe when it was perceived as a painful sensation. Table 2 summarizes the assessment criteria.

\section{Cosmetic Outcome and Patient Satisfaction}

Functional outcome was assessed with a focus on ocular dystopia and periorbital and eyelid swelling. Ocular dystopia was graded according to patient perception.

Patient satisfaction was evaluated by telephone interviews. During these interviews, we made efforts to help the patients to discriminate between pathology-related and approach-related morbidity and to evaluate how the latter affected their quality of life (QOL). A specific targeted questionnaire was prepared to include only very precise questions to investigate and differentiate the impact of potential sequelae of the FOZ approach on patient QOL (Fig. 1).

\section{Surgical Technique}

The surgical FOZ-approach technique we adopted has been described extensively. ${ }^{34,36}$

\section{Skin Incision}

The incision begins less than $1 \mathrm{~cm}$ anterior to the tragus on the side of the craniotomy, and while staying behind the hairline, it is extended to the controlateral frontal area to allow enough reflection to expose the orbital rim. The fat layer between the 2 temporal fascial layers is dissected deeply to avoid injury to the frontal branch of the facial nerve. The dissection continues subperiosteally until the larger part of the frontal process of the zygoma is exposed. The muscle is elevated from its attachment on the inferior part of the temporal line and from the zygoma in a retrograde direction following the direction of the muscle fibers.

\section{Craniotomy}

A standard frontotemporal craniotomy is performed. The sphenoid wing is rongeured and drilled. The orbito- meningeal artery is identified, coagulated, and cut. The base of the anterior clinoid is then evident.

\section{Orbitozygomatic Osteotomy}

The frontal and temporal dura mater is separated from the roof and lateral wall of the orbit. The superior orbital fissure (SOF) is identified extradurally just medial to the entrance point of the orbitomeningeal artery. Next, the periorbita is gently separated from the lateral wall and the roof of the orbit for at least $3 \mathrm{~cm}$ posterior to the orbital rim. The supraorbital nerve and vessels are identified along the medial third of the superior orbital rim. The bundle should be spared and freed with a chisel and mallet when it runs in a notch or with a high-speed drill if it runs in a bony canal. The first sagittal cut is made with a thin saw blade in the superior orbital rim, and a second cut is made on the lateral orbital rim immediately superior to the body of the zygoma toward the inferior orbital fissure. These 2 cuts, starting from the inferior orbital fissure on the lateral orbital wall just anterior to the SOF and curving and continuing in a posteroanterior sagittal direction, are connected using a high-speed drill with a cutting bur.

\section{Extradural Optic Nerve Decompression}

Under microscope magnification, the optic canal is unroofed using a high-speed drill with a diamond bur while under continuous irrigation. The optic nerve dural sheet is completely exposed superiorly and as much as possible laterally and medially. Care is taken to not enter the sphenoid sinus medial to the optic canal.

\section{Reconstruction and Closure}

The orbital flap is fixed first using titanium miniplates. The bone flap of the vault is placed in contact with the orbitotomy flap in the frontal region to avoid postoperative skin depression. Any excessive bone gap caused by using the craniotome can be covered with strips of titanium mesh screwed into the bone. The temporalis muscle is approximated and sutured. In the most anterior part near the zygoma, the muscle is attached to the skull by passing a stitch through a small hole drilled in the zygomatic process of the frontal bone. The skin is closed, and a subgaleal drain is left in place.

\section{Duration of Surgery}

For 20 patients who underwent surgery in 2014, we also recorded the time needed for the FOZ approach and for the orbitotomy and orbital reconstruction, performed by a surgeon trained in this specific approach. 


\section{PATIENT'S DATA}

1) Patient: Date of birth:

2) Date of surgical operation: Pathology:

3) Other pathologies:

4) Follow-up (months):

5) Side: RIGHT $\square$ LEFT $\square \quad$ Optic nerve decompression: NO $\square$ YES $\square$

6) Preoperative diplopia: NO $\square$ YES $\square \quad$ Notes:

7) Preoperative exophthalmos: NO $\square$ YES $\square$ Grade: Mild $\square$ Moderate $\square$ Severe $\square$

8) Complications:

9) Exophthalmos at follow-up MRI: NO $\square$ YES $\square \quad$ Grade: Mild $\square$ Moderate $\square$ Severe $\square$

10) Enophthalmos at follow-up MRI: NO $\square$ YES $\square \quad$ Grade: Mild $\square$ Moderate $\square$ Severe $\square$

\section{TELEPHONE QUESTIONNAIRE}

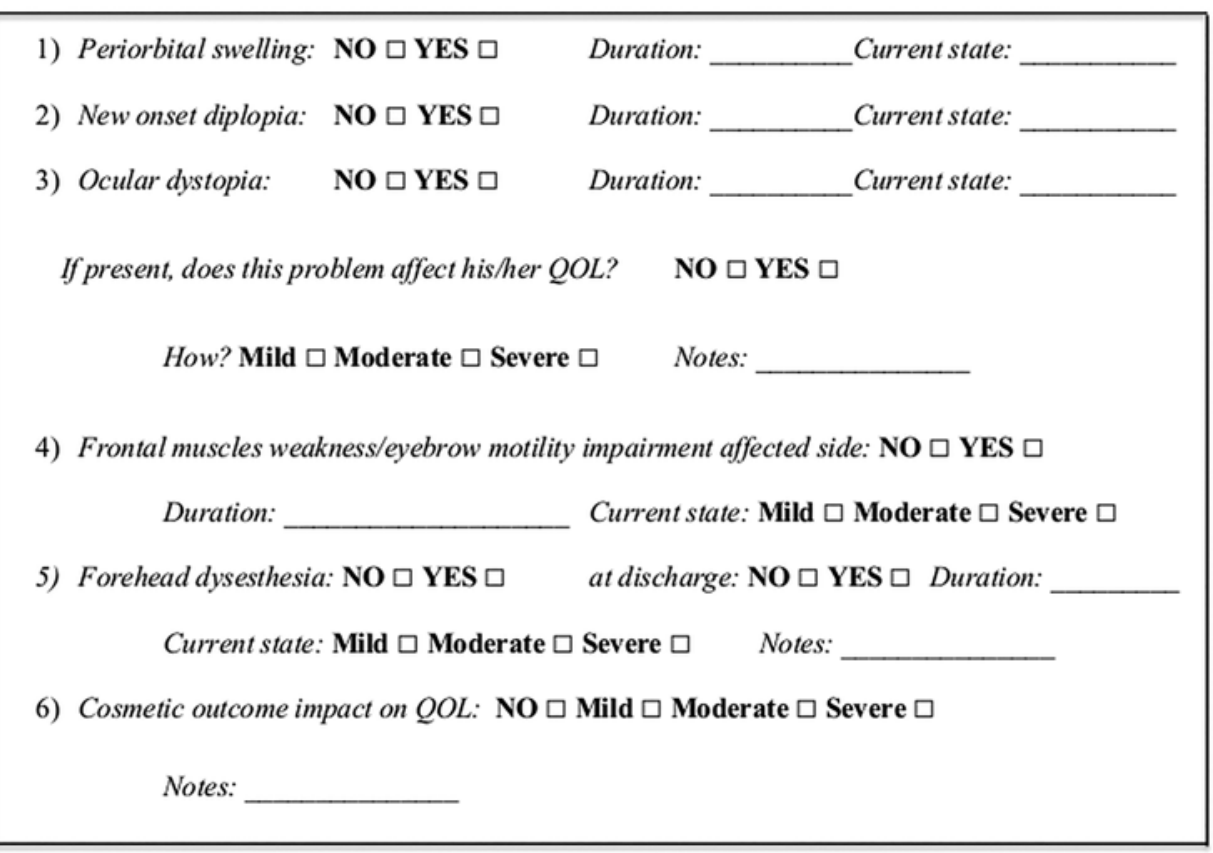

FIG. 1. English translation of the questionnaire administered to patients.

\section{Results}

\section{Surgical Complications}

In $5(3.0 \%)$ cases, CSF rhinorrhea caused by a CSF leak through the frontal sinus was recorded; in 4 (2.4\%) cases, the symptom was resolved after external lumbar drainage, and in $1(0.6 \%)$ case, revision surgery for sealing of the frontal sinus was needed. Table 3 summarizes surgical complications, functional and cosmetic outcomes, and patient-satisfaction data.

\section{Functional Outcome}

Among the 79 patients who underwent extradural optic nerve decompression for preoperative visual impairment, $5(6.3 \%)$ experienced worsening of visual function after surgery, but only in $1(1.3 \%)$ case was it likely related to the extradural optic nerve decompression. In 18 (10.7\%) patients, diplopia that resulted from ocular movement impairment was present at hospital admission. Thirty-nine (25.8\%) of 151 patients complained of new-onset postoperative diplopia that resulted from ocular movement impairment; in $29(19.2 \%)$ cases, it was transient, and the mean time for resolution was 1 month (range 1-12 months; SD 3 months), and in 10 (6.6\%) cases, it was permanent. Among the patients in whom it was permanent, the diplopia in 7 
TABLE 3. Surgical complications, cosmetic and functional outcomes, and impact on QOL

\begin{tabular}{|c|c|c|c|c|c|c|}
\hline \multirow[b]{2}{*}{ Outcome } & \multirow[b]{2}{*}{$\begin{array}{l}\text { Population } \\
\text { No. }\end{array}$} & \multirow{2}{*}{$\begin{array}{c}\text { Complication } \\
\text { Rate (No. } \\
[\%])\end{array}$} & \multicolumn{2}{|c|}{ Transient Complications } & \multirow{2}{*}{$\begin{array}{c}\text { No. }(\%) \text { of } \\
\text { Permanent } \\
\text { Complications }\end{array}$} & \multirow[b]{2}{*}{ Grade (\%) } \\
\hline & & & $\begin{array}{l}\text { No. } \\
(\%)\end{array}$ & $\begin{array}{l}\text { Mean Resolution } \\
\text { Time (days) }\end{array}$ & & \\
\hline \multicolumn{7}{|l|}{ Surgical complication } \\
\hline CSF rhinorrhea & 169 & $5(3.0)$ & - & - & - & - \\
\hline \multicolumn{7}{|l|}{ Cosmetic outcome } \\
\hline Ocular dystopia & 169 & - & - & - & $7(4.1)$ & - \\
\hline Orbital swelling & 169 & $124(73.4)$ & $119(70.4)$ & 34.3 & $5(3)$ & - \\
\hline \multicolumn{7}{|l|}{ Functional outcome } \\
\hline Visual worsening* & 79 & $5(6.3) \dagger$ & - & - & $5(6.3)$ & - \\
\hline Exophthalmos & 138 & $5(3.6)$ & $3(2.2)$ & - & $2(1.4)$ & $2(100)$ mild \\
\hline Enophthalmos & 169 & $7(4.1)$ & 0 & - & $7(4.1)$ & 5 (71.4) mild, 2 (28.6) moderate \\
\hline Diplopia & 151 & $39(25.8)$ & $29(19.2)$ & 33.2 & $10(6.6) \ddagger$ & - \\
\hline Forehead skin hypesthesia & 169 & $83(49.1)$ & $13(7.7)$ & 150 & $70(41.4)$ & - \\
\hline Forehead skin dysesthesia & $70 \S$ & $27(16)$ & $1(0.6)$ & - & $26(15.3)$ & 19 (73) mild, 6 (23) moderate, 1 (4) severe \\
\hline Frontal muscle weakness & 165 & $17(10.3)$ & - & - & $17(10.3)$ & $\begin{array}{l}12 \text { (70.6) mild, } 3 \text { (17.6) moderate, } \\
2 \text { (11.8) severe }\end{array}$ \\
\hline Impact on QOL & - & - & - & - & - & $\begin{array}{l}123 \text { (72.8) not disabling, } 29 \text { (17.2) mild, } \\
14 \text { (8.3) moderate, } 3 \text { (1.8) severe }\end{array}$ \\
\hline
\end{tabular}

(4.6\%) patients was likely a result of the surgical maneuvers needed to dissect the tumor from the nerves, and only in $3(2 \%)$ cases does it have to be considered a complication related to the surgical approach. Preoperative exophthalmos was detected in $31(18.3 \%)$ patients at hospital admission. New-onset exophthalmos in $5(3.6 \%)$ of 138 patients was recorded; in $3(2.2 \%)$ cases, it was transient, and in the other $2(1.4 \%)$ cases, it was permanent, although both cases were classified as mild $(<2 \mathrm{~mm})$. Postoperative enophthalmos was recorded in 7 (4.1\%) cases; 5 (3\%) cases were classified as mild $(<2 \mathrm{~mm})$, and $2(1.2 \%)$ cases were classified as moderate $(\geq 2$ but $<4 \mathrm{~mm}$ ).

New-onset permanent frontal muscle weakness and eyebrow motility impairment were recorded in $17(10 \%)$ patients; the degree of residual paresis at follow-up was mild in $12(70.6 \%)$ cases, moderate in $3(17.6 \%)$ cases, and severe in $2(11.8 \%)$ cases.

New-onset postoperative forehead skin hypesthesia was recorded in 83 (49.1\%) cases; in 13 (7.7\%) of these cases, it was transient, and the mean time for resolution was 5 months (range 1-9 months; SD 3 months). In 70 (41.4\%) patients, the hypesthesia was permanent; among them, $27(16 \%)$ also complained of disturbing or painful dysesthesia.

Permanent forehead dysesthesia (26 cases) was classified as mild in $19(73 \%)$ cases, moderate in $6(23 \%)$ cases, and severe in $1(3.8 \%)$ case.

\section{Cosmetic Outcome and Patient Satisfaction}

Seven $(4.1 \%)$ patients complained of subjective ocular dystopia in the postoperative period. Periorbital and eyelid swelling was detected in $124(73.4 \%)$ patients before hospital discharge; in 119 (70.4\%) patients, it was transient with a mean time for resolution of 1 month (range $0-0.5$ months; SD 2.5 months), and in 5 (3\%) cases, it was permanent.

Among the 169 patients who participated in the telephone questionnaire, $123(72.8 \%)$ were satisfied with the cosmetic outcome and did not think that the surgery had affected their QOL negatively, 29 (17.2\%) thought that surgery had a mild negative effect on their QOL, $14(8.3 \%)$ complained of a moderate negative effect on their QOL, and $3(1.8 \%)$ complained of a severe disabling effect.

\section{Duration of Surgery}

The mean time needed for the whole FOZ approach (frontotemporal approach, orbitotomy, and orbital reconstruction) was 43 minutes (range 27-83 minutes; SD 14.9 minutes); extradural optic nerve decompression was performed in 9 of these patients, and in their cases, the mean time for the whole approach (FOZ and extradural optic nerve decompression) was 63.8 minutes (range 49-83 minutes; SD 11.7 minutes). The mean time needed for orbitotomy was 19.9 minutes (range 10-31 minutes; SD 5.8 minutes), and the mean time needed for orbital reconstruction was 7.3 minutes (range 4-13 minutes; SD 2.5 minutes); therefore, the additional mean time needed for orbitotomy and orbital reconstruction was 27.2 minutes (range 14-44 minutes; SD 7.9 minutes).

\section{Discussion}

This study was focused on the functional and cosmetic outcomes of surgery performed through the FOZ approach regardless of the pathology treated. The rationale 
for using the FOZ approach can vary considering different pathologies.

In 1997, Mortini and Giovanelli ${ }^{36}$ introduced the FOZ approach at I.R.C.C.S. San Raffaele University Hospital, and a significant improvement in patient visual outcome was found. In 13 patients treated for a pituitary tumor through the FOZ approach with extradural and intradural optic nerve decompression, postoperative visual function improved in $61.5 \%$, was unchanged in $23.1 \%$, and worsened in $15.4 \%{ }^{36}$ These results were compared with a control group of our last 15 patients who underwent surgery for the same disease through the standard frontopterional approach ${ }^{36}$ In this control group whose surgery was performed through the FOZ approach, postoperative visual function improved in $26.6 \%$, was unchanged in $33.4 \%$, and worsened in $40 \% .{ }^{36}$ According to these results, we deduced that extradural and intradural decompression of the optic nerve are easily allowed by the FOZ approach, have a protective effect, and decrease postoperative worsening of visual function. ${ }^{36}$

In 2000, we adopted the FOZ approach as the standard transcranial approach for treating, in particular, sellar and parasellar tumors that cause optic nerve compression (e.g., giant pituitary adenomas, craniopharyngiomas, tuberculum sellae meningiomas), and we rely on the following

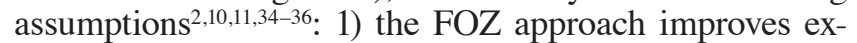
posure of the skull base and minimizes brain retraction ${ }^{34}$; 2) the FOZ approach enables quick and safe extradural unroofing of the optic canal and intradural incision of the dural sheath ${ }^{34}$ (these 2 surgical steps enable early identification and decompression of the optic nerve so that it can be safely mobilized for the inspection on its inferior, medial, and lateral surfaces); and 3) for other pathologies, such as orbital cavernoma, the FOZ approach is useful for gaining access to tumors located in the orbital apex and in the superomedial compartment of the orbit. ${ }^{10}$

In the present series, pathologies treated using the FOZ approach (Table 1) were mostly sellar and parasellar meningiomas (50\% of cases), followed by craniopharyngiomas and pituitary adenomas (30\% of cases); other pathologies included orbital cavernomas (5.3\%) and aneurysms (4.7\%). The same surgical technique was applied in all patients by using a standard frontotemporal approach followed by an orbitotomy including the zygomatic process of the frontal bone. ${ }^{10,11,34-37}$ Reconstruction was performed using titanium miniplates and screws and titanium meshes when a significant bone gap was present.

We made significant efforts to discriminate approachrelated complications from those related to the surgical treatment of the pathology; preoperative neurological deficits were recorded accurately, but neurological deficits related to the surgical treatment of the pathology were not considered in the results. Furthermore, cosmetic issues that are not specific to the FOZ approach were not considered. The rationale for this choice was our attempt to understand the specific clinical impact of the orbitotomy in the FOZ approach when compared with that of the standard frontotemporal approach. In 2012, Youssef et al..$^{56}$ reported on a series of 75 patients who underwent surgery in which the frontotemporoorbitozygomatic approach was used. The main difficulty in comparing results of our study with those reported by the aforementioned study is that Youssef et al. ${ }^{56}$ stratified their patients and results according to the variant of the FOZ approach used and to the underlying pathology of the patients. Therefore, our study represents, to our knowledge, the only available retrospective study in which clinical outcomes in a large population of patients who underwent surgery with the FOZ approach with the same technique were evaluated with a focus on complications caused by the approach regardless the treated pathology.

\section{Surgical Complications}

Approach-related CSF leakage usually occurred with CSF rhinorrhea caused by a pseudomeningocele associated with ineffective sealing of the frontal sinus or incidental opening of the sphenoid sinus and its mucosa during extradural optic nerve decompression. In our series, we recorded $5(3.0 \%)$ cases of CSF rhinorrhea; in 4 cases, CSF leakage stopped after 5 days of external lumbar drainage, and in only $1(0.6 \%)$ case was revision surgery with sealing of the frontal sinus with a pedicled pericranial flap needed. During orbital osteotomy, opening of the frontal sinus is a common finding. ${ }^{11,36,44}$ To preserve normal sinus anatomy and function, we do not remove sinus mucosa; before orbital reconstruction, we usually harvest a small pedicled frontal pericranial flap and position it over the opening of the sinus. It is then fixed with stiches passed through small holes made in the anterior and posterior walls of the sinus; fibrin glue is used to seal the sinus. If violation of the sphenoid sinus and its mucosa occurs during extradural optic nerve decompression and drilling medially to the nerve, a small piece of temporal muscle is plugged into the opening and fixed with fibrin glue.

\section{Functional Outcome}

In only $1(1.3 \%)$ of 79 cases was postoperative visual worsening likely related to surgical unroofing of the optic canal, probably in relation to thermal damage. For this reason, we recommend that extradural optic nerve decompression be performed using diamond burs under abundant saline irrigation.

Transient diplopia after surgery was recorded in 29 cases (10.2\% of patients who not present with diplopia before surgery); the mean time for resolution was approximately 1 month. Periorbital and eyelid swelling was a very common finding after surgery through the FOZ approach (73.4\% of cases); transient diplopia could be related to ocular dystopia as a result of orbital and periorbital edema. Permanent diplopia likely related to the surgical approach was recorded in 3 (2\%) cases. Approach-related diplopia could be caused by direct injury to the nerves passing in the SOF during orbital osteotomy, by an inaccurate orbital reconstruction (which can lead to extrinsic ocular muscle entrapment), or by significant postoperative ocular dystopia. ${ }^{11,36}$ The orbitomeningeal artery represents an important landmark during orbital osteotomy; the bony canal of the artery represents the posterior limit of the osteotomy for avoiding possible violation of the SOF ${ }^{36}$ During orbital reconstruction, avoiding entrapment of the periorbita and extrinsic orbital muscles between the bone edges of the orbit is crucial. 
Transient postoperative exophthalmos was recorded in 3 cases and could have been the result of orbital swelling; in 2 cases, permanent exophthalmos $(<2 \mathrm{~mm})$ was recorded, and it was probably the consequence of a defective orbital reconstruction. Postoperative enophthalmos in 7 patients ( $\geq 2 \mathrm{~mm}$ in only 2 cases), probably caused by an inability to restore normal orbital volume after removal of a tumor (e.g., sphenoid wing meningioma, orbital tumor), was recorded. Slow-growing tumors, such as intraorbital benign tumors, can progressively cause proptosis and accompanying orbital fat-volume reduction; therefore, after tumor removal through the FOZ approach, an accurate orbital reconstruction can result in mild enophthalmos. ${ }^{11}$ Frontal muscle weakness and eyebrow motility impairment can be the result of an injury to the frontal branch of the facial nerve during exposure of the zygomatic process of the frontal bone. ${ }^{16,20,29,33,49,55}$ We routinely perform interfascial dissection, which leaves the nerve in the fat layer between the 2 temporal fasciae to protect it during surgical maneuvers. ${ }^{36,53,55}$ Nevertheless, in this series, we recorded 12 cases of mild paresis (not perceived by the patient), 8 cases of moderate paresis, and 2 cases of complete paresis. Damage to the nerve probably occurred during interfascial dissection of the temporal muscle or as a consequence of prolonged retraction of the muscle. Forehead hypesthesia and dysesthesia can be consequences of supraorbital nerve injury during its release from the supraorbital notch or foramen before orbital osteotomy is performed. ${ }^{36}$ In our series, we recorded a significantly high occurrence of postoperative hypesthesia (41\% of patients); in 27 patients, hypesthesia was associated with dysesthesia that was felt by 6 patients to be disturbing and 2 patients to be severe and disabling.

\section{Cosmetic Outcome and Patient Satisfaction}

Ocular dystopia subjectively perceived by 7 patients to be cosmetically disabling was recorded and, as mentioned earlier, might have been related to an improper orbital reconstruction. Periorbital eyelid swelling is a common postoperative event that results from blood and serum collection in the orbit and periorbital tissues. It usually improves 3 days after surgery but, in $73.3 \%$ of the patients, was still present at the moment of hospital discharge; the mean resolution time was approximately 1 month (range 1-8 months; SD 3.6 months). In the early postoperative period, eyelid swelling is usually present in the early morning and tends to disappear while the patient is in an orthostatic position during the day. Only 5 (3\%) patients complained of a persistent problem at follow-up.

All the patients included in this study answered the telephone questionnaire. The questionnaire was structured to investigate how patients perceived the possible complications of the FOZ approach and how these complications would affect their QOL. One hundred twenty-three $(72.8 \%)$ patients answered that the approach did not affect their QOL, 29 (17.2\%) patients complained of minor problems that influenced their QOL slightly, 14 (8.3\%) patients answered that surgery had affected their life negatively even if they were continuing to do the same things they did before surgery, albeit while experiencing daily problems, and only $3(1.8 \%)$ patients reported that they were unable to live a normal life and that surgery had had a severe negative impact on their QOL. Among these patients, 2 suffered from permanent diplopia, and 1 complained of frontal burning dysesthesia.

\section{Duration of Surgery}

In 2014, the duration of surgery in the 20 patients included in the study was surveyed and recorded to evaluate the mean additional time needed to perform orbitotomy and orbital reconstruction. The mean time needed for the 2 additional steps of the FOZ approach compared with the frontotemporal approach was 27.2 minutes.

According to these data, we can assert that the FOZ approach, if performed by a trained surgeon, does not affect the duration of surgery significantly.

\section{Limitations of the Study}

The first limitation of this study was the difficulty we encountered in properly and retrospectively differentiating approach-related complications from those related to the surgical treatment for the pathology. This bias can be heightened significantly in the subjective evaluation of patients regarding the effect of surgery on their QOL.

Other important limitations were the retrospective nature of the study and the absence of a control group of patients who underwent surgery through a standard frontotemporal approach. Furthermore, patients included in this series underwent surgery through an FOZ approach for different pathologies that could have affected their functional and cosmetic outcomes. Ideally, a study comparing morbidity and cosmetic and functional results in 2 cohorts of patients who harbor the same pathology and underwent surgery through a frontotemporal approach or through an FOZ approach should have significant utility in daily clinical practice. In our opinion, such a study would be very complex to perform, even retrospectively, because of the relative rarity of the pathologies treated through the FOZ approach and because it should be done in a high-volume center in which the same pathologies are treated in the same period by the same group of surgeons using different approaches; nevertheless, it could be helpful for surgeons in balancing the well-known benefits of the approach and potential morbidities and making the best decision in relation to the pathology with which they are dealing.

\section{Conclusions}

The FOZ approach has been considered the true workhorse of skull base surgery because of its well-known advantages in terms of the increased exposure of the sellar and parasellar regions it affords and its simple execution, great versatility, and low associated morbidity rate. In this study, clinical outcomes in a large series of 169 patients who underwent surgery through the FOZ approach were evaluated with a focus on approach-related complications as determinants of functional and cosmetic outcomes and patient satisfaction. Approximately $90 \%$ of the patients reported that surgery had not affected their QOL significantly. Comprehensive knowledge of the potential complications and the overall clinical outcome from the FOZ approach can be of great utility to neurosurgeons in bal- 
ancing the well-known benefits of the approach and the potential additional morbidities.

\section{References}

1. Al-Mefty O: Skull base: zygomatic approach. Neurosurgery 19:674-675, 1986 (Letter)

2. Al-Mefty O: Supraorbital-pterional approach to skull base lesions. Neurosurgery 21:474-477, 1987

3. Al-Mefty O, Anand VK: Zygomatic approach to skull-base lesions. J Neurosurg 73:668-673, 1990

4. Al-Mefty O, Smith RR: Tailoring the cranio-orbital approach. Keio J Med 39:217-224, 1990

5. Alaywan M, Sindou M: Fronto-temporal approach with orbito-zygomatic removal. Surgical anatomy. Acta Neurochir (Wien) 104:79-83, 1990

6. Altay T, Couldwell WT: The frontotemporal (pterional) approach: an historical perspective. Neurosurgery 71:481-492, 2012

7. Aziz KM, Froelich SC, Cohen PL, Sanan A, Keller JT, van Loveren HR: The one-piece orbitozygomatic approach: the MacCarty burr hole and the inferior orbital fissure as keys to technique and application. Acta Neurochir (Wien) 144:1524, 2002

8. Balasingam V, Noguchi A, McMenomey SO, Delashaw JB Jr: Modified osteoplastic orbitozygomatic craniotomy. Technical note. J Neurosurg 102:940-944, 2005

9. Behari S, Das RK, Jaiswal AK, Jain VK: Fronto-temporoorbitozygomatic craniotomy and "half-and-half" approach for basilar apex aneurysms. Neurol India 57:438-446, 2009

10. Boari N, Gagliardi F, Castellazzi P, Mortini P: Surgical treatment of orbital cavernomas: clinical and functional outcome in a series of 20 patients. Acta Neurochir (Wien) 153:491498, 2011

11. Boari N, Gagliardi F, Spina A, Bailo M, Franzin A, Mortini P: Management of spheno-orbital en plaque meningiomas: clinical outcome in a consecutive series of 40 patients. Br $\mathbf{~ J}$ Neurosurg 27:84-90, 2013

12. Cappabianca P, Califano L, Iaconetta G: Cranial, Craniofacial and Skull Base Surgery. Milan: Springer, 2010

13. Chanda A, Nanda A: Anatomical study of the orbitozygomatic transsellar-transcavernous-transclinoidal approach to the basilar artery bifurcation. J Neurosurg 97:151-160, 2002

14. Chang CW, Wang LC, Lee JS, Tai SH, Huang CY, Chen HH: Orbitozygomatic approach for excisions of orbital tumors with 1 piece of craniotomy bone flap: 2 case reports. Surg Neurol 68 (Suppl 1):S56-S59, 2007

15. Conway JE, Raza SM, Li K, McDermott MW, QuiñonesHinojosa A: A surgical modification for performing orbitozygomatic osteotomies: technical note. Neurosurg Rev 33:491-500, 2010

16. Coscarella E, Vishteh AG, Spetzler RF, Seoane E, Zabramski JM: Subfascial and submuscular methods of temporal muscle dissection and their relationship to the frontal branch of the facial nerve. Technical note. J Neurosurg 92:877-880, 2000

17. Deda H: Orbitozygomatic approach to skull base lesions. Turk Neurosurg 10:43-47, 2000

18. Donald PJ: History of skull base surgery. Skull Base Surg 1:1-3, 1991

19. Donald PJ: Surgery of the Skull Base. Philadelphia: Lippincott-Raven, 1998

20. Elazab EE, Abdel-Hameed FA: The arterial supply of the temporalis muscle. Surg Radiol Anat 28:241-247, 2006

21. Golshani KJ, Lalwani K, Delashaw JB, Selden NR: Modified orbitozygomatic craniotomy for craniopharyngioma resection in children. J Neurosurg Pediatr 4:345-352, 2009

22. Guerrero Jazo FJ: New orbitozygomatic approach by craniotomy. Childs Nerv Syst 20:50-54, 2004

23. Gupta SK, Khosla VK, Sharma BS: Bilateral fronto-orbito- zygomatic craniotomy-a combined extended frontal and orbitozygomatic approach. Neurol India 48:361-364, 2000

24. Gupta SK, Sharma BS, Pathak A, Khosla VK: Single flap fronto-temporo-orbito-zygomatic craniotomy for skull base lesions. Neurol India 49:247-252, 2001

25. Guyer DR, Miller NR, Long DM, Allen GS: Visual function following optic canal decompression via craniotomy. J Neurosurg 62:631-638, 1985

26. Hakuba A, Liu S, Nishimura S: The orbitozygomatic infratemporal approach: a new surgical technique. Surg Neurol 26:271-276, 1986

27. Hayashi N, Hirashima Y, Kurimoto M, Asahi T, Tomita T, Endo S: One-piece pedunculated frontotemporal orbitozygomatic craniotomy by creation of a subperiosteal tunnel beneath the temporal muscle: technical note. Neurosurgery 51:1520-1524, 2002

28. Ikeda K, Yamashita J, Hashimoto M, Futami K: Orbitozygomatic temporopolar approach for a high basilar tip aneurysm associated with a short intracranial internal carotid artery: a new surgical approach. Neurosurgery 28:105-110, 1991

29. Kadri PA, Al-Mefty O: The anatomical basis for surgical preservation of temporal muscle. J Neurosurg 100:517-522, 2004

30. Lee JP, Tsai MS, Chen YR: Orbitozygomatic infratemporal approach to lateral skull base tumors. Acta Neurol Scand 87:403-409, 1993

31. Lemole GM Jr, Henn JS, Zabramski JM, Spetzler RF: Modifications to the orbitozygomatic approach. Technical note. J Neurosurg 99:924-930, 2003

32. McArthur LL: An aseptic surgical access to the pituitary body and its neighborhood. JAMA 58:2009-2011, 1912

33. Monkhouse WS: The anatomy of the facial nerve. Ear Nose Throat J 69:677-683, 686-687, 1990

34. Mortini P, Barzaghi LR, Serra C, Orlandi V, Bianchi S, Losa M: Visual outcome after fronto-temporo-orbito-zygomatic approach combined with early extradural and intradural optic nerve decompression in tuberculum and diaphragma sellae meningiomas. Clin Neurol Neurosurg 114:597-606, 2012

35. Mortini P, Barzaghi R, Losa M, Boari N, Giovanelli M: Surgical treatment of giant pituitary adenomas: strategies and results in a series of 95 consecutive patients. Neurosurgery 60:993-1004, 2007

36. Mortini P, Giovanelli M: Transcranial approaches to pituitary tumors. Oper Tech Neurosurg 5:239-251, 2002

37. Mortini P, Losa M, Pozzobon G, Barzaghi R, Riva M, Acerno $S$, et al: Neurosurgical treatment of craniopharyngioma in adults and children: early and long-term results in a large case series. J Neurosurg 114:1350-1359, 2011

38. Ormond DR, Hadjipanayis CG: The history of neurosurgery and its relation to the development and refinement of the frontotemporal craniotomy. Neurosurg Focus 36(4):E12, 2014

39. Pellerin P, Lesoin F, Dhellemmes P, Donazzan M, Jomin M: Usefulness of the orbitofrontomalar approach associated with bone reconstruction for frontotemporosphenoid meningiomas. Neurosurgery 15:715-718, 1984

40. Pieper DR, Al-Mefty O: Cranio-orbito-zygomatic approach. Oper Tech Neurosurg 2:2-9, 1999

41. Rohde V, Schaller K, Hassler W: The combined pterional and orbitocygomatic approach to extensive tumours of the lateral and latero-basal orbit and orbital apex. Acta Neurochir (Wien) 132:127-130, 1995

42. Santoro A, Salvati M, Vangelista T, Delfini R, Cantore GP: Fronto-temporo-orbito-zygomatic approach and variants. Surgical technique and indications. J Neurosurg Sci 47:141147,2003

43. Seçkin H, Avci E, Uluç K, Niemann D, Başkaya MK: The work horse of skull base surgery: orbitozygomatic approach. Technique, modifications, and applications. Neurosurg Focus 25(6):E4, 2008 
44. Sekhar LN, Nanda A, Sen CN, Snyderman CN, Janecka IP: The extended frontal approach to tumors of the anterior, middle, and posterior skull base. J Neurosurg 76:198-206, 1992

45. Shigeno T, Tanaka J, Atsuchi M: Orbitozygomatic approach by transposition of temporalis muscle and one-piece osteotomy. Surg Neurol 52:81-83, 1999

46. Sindou M, Alaywan M: [Orbital and/or zygomatic removal in an approach to lesions near the cranial base. Surgical technic, anatomic study and analysis of a series of 24 cases.] Neurochirurgie 36:225-233, 1990 (Fr)

47. Sindou M, Emery E, Acevedo G, Ben-David U: Respective indications for orbital rim, zygomatic arch and orbito-zygomatic osteotomies in the surgical approach to central skull base lesions. Critical, retrospective review in 146 cases. Acta Neurochir (Wien) 143:967-975, 2001

48. Spallone A, Rizzo A, Konovalov AN, Giuffre R: Frontoorbito zygomatic approach: a technical modification. Skull Base Surg 6:125-128, 1996

49. Spetzler RF, Lee KS: Reconstruction of the temporalis muscle for the pterional craniotomy. Technical note. J Neurosurg 73:636-637, 1990

50. Tanriöver N, İsler C, Sanus GZ, Ak H, Canbaz B, Akar ZC: Cranio-orbitozygomatic approach and its orbitopterional modification: microsurgical anatomy and surgical technique. Turk Neurosurg 16:175-184, 2006

51. Tanriover N, Ulm AJ, Rhoton AL Jr, Kawashima M, Yoshioka N, Lewis SB: One-piece versus two-piece orbitozygomatic craniotomy: quantitative and qualitative considerations. Neurosurgery 58 (4 Suppl 2):ONS-229-ONS-237, 2006

52. van Furth WR, Agur AM, Woolridge N, Cusimano MD: The orbitozygomatic approach. Neurosurgery 58 (1 Suppl):ONS103-ONS107, 2006

53. Yaşargil MG: Microneurosurgery. Stuttgart: Thieme, 1984, Vol I
54. Yaşargil MG: Microsurgery Applied to Neurosurgery. Stuttgart: Thieme, 1969

55. Yaşargil MG, Reichman MV, Kubik S: Preservation of the frontotemporal branch of the facial nerve using the interfascial temporalis flap for pterional craniotomy. Technical article. J Neurosurg 67:463-466, 1987

56. Youssef AS, Willard L, Downes A, Olivera R, Hall K, Agazzi S, et al: The frontotemporal-orbitozygomatic approach: reconstructive technique and outcome. Acta Neurochir (Wien) 154:1275-1283, 2012

57. Zabramski JM, Kiriş T, Sankhla SK, Cabiol J, Spetzler RF: Orbitozygomatic craniotomy. Technical note. J Neurosurg 89:336-341, 1998

\section{Disclosures}

The authors report no conflict of interest concerning the materials or methods used in this study or the findings specified in this paper.

\section{Author Contributions}

Conception and design: Boari, Mortini. Acquisition of data: Spina, Giudice, Gorgoni. Analysis and interpretation of data: Boari, Spina, Giudice, Gorgoni, Bailo. Drafting the article: Spina, Giudice. Critically revising the article: Boari, Spina, Bailo, Mortini. Reviewed submitted version of manuscript: Boari, Spina, Mortini. Approved the final version of the manuscript on behalf of all authors: Boari. Study supervision: Boari, Mortini.

\section{Correspondence}

Nicola Boari, Department of Neurosurgery and Gamma Knife Radiosurgery, I.R.C.C.S. San Raffaele University Hospital, Via Olgettina 60, Milan 20132, Italy. email: boari.nicola@hsr.it. 